Original article

\title{
EFFECTIVENESS OF DEEP BREATHING EXERCISE (DBE) ON THE HEART RATE VARIABILITY, BP, ANXIETY \& DEPRESSION OF PATIENTS WITH CORONARY ARTERY DISEASE
}

\author{
Fatima D'silva', Vinay H. $^{2} \&$ N.V. M uninarayanappa ${ }^{3}$ \\ ${ }^{1,3}$ Principal, ${ }^{2}$ Student M Sc. (N), Nitte Usha Institute of Nursing Sciences, Nitte University, Paneer, M angalore, \\ ${ }^{3}$ Principal / Dean, School of Nursing Sciences and Research, Sharda University, Greater Noida \\ Correspondence: \\ Fatima D'silva \\ Principal, Nitte Usha Institute of Nursing Sciences, Nitte University, Paneer, M angalore - 575018 \\ Mobile : +919945064006 E-mail : ftds_1970@ rediffmail.com
}

\begin{abstract}
:
Psychosocial risk factors significantly contribute to the morbidity and mortality of patients with cardiovascular disorders. The present study explored the anxiety and depression status of patients with coronary artery disease and evaluated the effect of deep breathing exercise on these psychosocial variables as well as physiological variables like heart rate variability and blood pressure. A randomized control design was adopted for the study. Out of 65 clients eligible for the study, 45 were selected based on inclusion criteria. Patient were trained in Deep breathing exercise (DBE)for 2-3 days, were instructed to practice the exercise twice a day for 10 min for a period of 2 weeks, further instructed to come for follow up to cardiac OPD after 2 weeks. The study findings revealed that majority of the cardiac patients were anxious $39(86.66 \%), 23(57.5 \%)$ had mild depression and 3(7.5\%) were with severe depression. Fischer's exact test revealed a significant association between depression and occupation $(p=0.051)$, monthly income $(p=0.031)$ and co morbid disease $(p=0.006, p<0.05)$. Karl Pearson's correlation coefficient revealed significant positive correlation between anxiety and depression i.e. ( $r$ $=0.414, p<0.01$ ). DBE was found to be effective in reducing anxiety and diastolic BP of clients with CAD. But there was no significant reduction in HR, SBP and depression after the intervention.
\end{abstract}

Keywords : Coronary artery disease (CAD), Deep breathing exercise (DBE), Heart rate variability, Blood pressure, Anxiety, Depression

\section{Introduction :}

The idea that emotions, feelings and social contexts contribute to heart disease is not a new one. For centuries, there has been popular, if not scientific, association between the heart and emotions. Therefore, normal emotional reactions to the development of heart disease often include aspects of shock, fear, anger, guilt, sadness and grief. ${ }^{1}$

Cardiovascular diseases encompass a number of diagnoses, including coronary heart disease, hypertension, and stroke, the three being Access this article online Quick Response Code

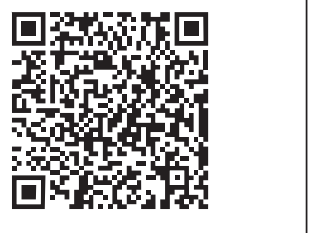

the most common conditions. Among them Coronary heart disease is the leading cause of death and is the result of atherosclerosis, or the build-up of fatty substances and other cellular products in the inner lining of coronary arteries, which decreases blood-flow to the heart and results in myocardial ischemia. ${ }^{2}$

Cardiovascular disease frequently coexists with psychiatric disorders. The co morbidity of psychiatric and cardiovascular disease is attributable not only to the cooccurrence of two independent illnesses, but also to the development of cardiac disease as a complication of emotional or psychiatric problems and conversely, the development of psychiatric disorders as complications of cardiovascular disease. ${ }^{1}$

The results of work conducted in the 20th century on cardiac disorder and associated psychosocial factors suggest that several psychosocial risk factors contribute to the development of cardiovascular disease and influence the course of those who have it. These risk factors included are anxiety, depression, anger, hostility, social isolation, stress. Anxiety is prevalent among patients with acute 
cardiac illness and triples the risk for all-cause mortality following myocardial infarction (MI), almost doubles the risk for re-infarction over 5 years. Several retrospective studies suggest that there is a high risk for cardiovascular complications from anxiety syndromes. ${ }^{3}$ Anxiety was significantly correlated with higher ambulatory blood pressure and heart rate in individuals who were monitored for emotional responsivity and physiological reactivity duringa 24 hour period. ${ }^{4}$

From data collected over 32 years in the prospective Normative Aging Study, male veterans who endorsed two or more symptoms of anxiety at baseline were significantly more likely to die of coronary heart disease, especially by sudden cardiac death, in comparison to those who reported no anxiety symptoms. ${ }^{5}$

Similar to anxiety, depression is a common problem in patients with heart disease, associated with reduced return to work and quality of life as well as increased mortality. Results from the National Health Examination Follow-Up Study found that those who had depressed affect at baseline were $50 \%$ more likely to die from heart disease by the 12-year follow-up point. 5 In a Canadian study of individuals who were diagnosed with myocardial infarction, of those who were depressed at baseline, 17\% had died at six-month follow-up, whereas only $3 \%$ of the non-depressed participants died within six-months. ${ }^{6}$

Depressed mood even in the absence of a clinical depressive disorder increases the risk for post MI period. Hence psychosocial risk factors need to be addressed in heart disease due to its high prevalence and negative effects. ${ }^{1}$

Hence psychological intervention programs coupled with coronary risk behavior interventions and exercise have a positive influence on both physical and psychosocial outcome of patients with coronary heart disease. Keeping this in mind the investigators have undertaken research in evaluating the efficacy of deep breathing exercise for depression and anxiety in patient with coronary artery disease.

\section{Objectives of the study}

1. To assess the baseline heart rate variability, blood pressure, anxiety, and depression level of patient with coronary artery disease.

2. To determine the effect of deep breathing exercise on heart rate variability, blood pressure, anxiety and depression of patients in experimental group.

3. To compare the heart rate variability and blood pressure scores, anxiety and depression level of patient between experimental and control group after intervention.

4. To find the association of base line heart rate, blood pressure, anxiety and depression level with selected demographic variables.

5. To find the correlation between heart rate, blood pressure, anxiety and depression of patients with coronary artery disease

\section{Materials and Methods:}

The study was conducted in K.S. Hegde Charitable Hospital, Mangalore. An experimental design was adopted for the study.

In the $1^{\text {st }}$ phase, 65 samples with coronary artery disease were enrolled into the study based on the diagnosis and inclusion criteria. 45 samples were eligible for the study and 20 were excluded based on exclusion criteria. In the 2nd phase informed consent was obtained from the eligible samples and they were randomly allocated to experimental (23) and control groups (22).

Initially physiological parameters like heart rate and blood pressure were monitored. Following this Beck's anxiety inventory and Beck's depression inventory-II was administered to the clients to know the baseline anxiety and depression levels. Clients in the experimental group were given training on deep breathing exercise for $20 \mathrm{~min}$ in two sessions of 10 min each with adequate rest in between for 2-3 days. To check the correctness of the deep breathing exercise patient were asked to re demonstrate the exercise and necessary corrections were given for the mistakes and patient's doubts were cleared. Patients were instructed to perform the exercise twice a day for $10 \mathrm{~min}$ 
for two weeks and to follow the instructions given and they were asked to make telephone call to the investigator regarding any doubts about the exercise while at home. Patients were followed for 2 weeks after training and they were asked to come to cardiac OPD after 2 weeks for the post data collection. During their visit to cardiac OPD, heart rate and blood pressure, anxiety and depression levels of clients were reassessed using the same tools. The control group was excluded from deep breathing exercise training but the Heart rate, Blood pressure, anxiety and depression levels were reassessed by using the same tools during their follow visit to the cardiac OPD.

The inclusion criteria for sample selection were,

1. Patients diagnosed with stable angina or post myocardial infarction who were medicallystable.

2. Patients who could read and write Kannada, Malayalam or English languages.

3. Patients identified with anxiety or depressive symptoms.

\section{Exclusion criteria}

1. Patient with known psychiatricillness

2. Patients who have undergone coronary artery bypass graft

3. Patient with other co morbid respiratory conditions.

4. Patients who were critically ill.

5. Patient with malignant hypertension.

6. Not willing to participate.
The data collection instruments included a demographic proforma comprising of nine items which included baseline information and clinical data. Standardized tools namely Beck's anxiety inventory and depression inventory - II (BDI) were also utilized for the study. Blood pressure of clients was assessed using a calibrated sphygmomanometer. Reliability of tools was established by Pearson's correlation coefficient formula and the reliability coefficient of the tool was found to be 0.75 for Beck's anxiety inventory and 0.80 for Beck's depression inventory-II. In the present study the cut off scores for depression was considered as 10 and scores were interpreted as follows:

No depression 0-9

Mild depression 10-30

M oderate depression 31-45

Severe depression 46-63

\section{Results:}

\section{Section I: Description of sample characteristics.}

M ajority of the samples 19(47.5\%) were in the age group of 50-59 years. $30(75 \%)$ were males. Majority of them 38 (95\%) were married. 28 (70\%) belonged to Hindu religion. $24(60 \%)$ had only primary education. 21 (52.5\%) were employed and had a monthly income between Rs.30015000. $32(80 \%)$ of the respondents were from nuclear family. Equal number 18 (45\%) of them were residents of urban and rural area. Majority of the clients 15 (37.5\%) were diagnosed with post myocardial infarction. 21 $(52.5 \%)$ were newly diagnosed with Coronary artery disease. 13 (32.5\%) were hypertensive, 9 (22.5\%) had both hypertension and diabetes. Only 5 (12.5\%) were diabetic.

Section II: Baseline heart rate and blood pressure scores, anxiety and depression level in experimental and control group

Table 1: Distribution of pretest heart rate scores of the clients in the experimental and control group

\begin{tabular}{|c|c|c|c|c|}
\hline $\begin{array}{c}\text { Heart rate } \\
\text { (beats/min) }\end{array}$ & \multicolumn{2}{|c|}{$\begin{array}{c}\text { Pretest heart rate scores } \\
\text { (Experimental group) }\end{array}$} & \multicolumn{2}{c|}{$\begin{array}{c}\text { Pretest heart rate scores } \\
\text { (control group) }\end{array}$} \\
\hline & Frequency (f) & Percentage (\%) & Frequency (f) & Percentage (\%) \\
\hline $62-72$ & 4 & 20 & 4 & 20 \\
\hline $72-80$ & 13 & 65 & 15 & 75 \\
\hline$>80$ & 3 & 15 & 1 & 5 \\
\hline Total & 20 & 100 & 20 & 100 \\
\hline
\end{tabular}


Table 2: Distribution of pretest systolic blood pressure scores of clients in the experimental and control group. $n=20+20$

\begin{tabular}{|c|c|c|c|c|}
\hline $\begin{array}{c}\text { SBP } \\
(\mathrm{mm} \text { of Hg) }\end{array}$ & \multicolumn{2}{|c|}{$\begin{array}{c}\text { Pretest SBP } \\
\text { (Experimental group) }\end{array}$} & \multicolumn{2}{c|}{$\begin{array}{c}\text { Pretest SBP } \\
\text { (Control group) }\end{array}$} \\
\hline 90-119 (Normal) & Frequency (f) & Percentage (\%) & Frequency (f) & Percentage (\%) \\
\hline $120-139$ ( Pre hypertension) & 1 & 5 & 2 & 10 \\
\hline $140-159$ (Stage-I Hypertension) & 5 & 60 & 8 & 40 \\
\hline$\geq 160$ (Stage -II Hypertension) & 2 & 25 & 6 & 30 \\
\hline Total & 20 & 10 & 4 & 20 \\
\hline
\end{tabular}

Table 3: Distribution of pretest diastolic blood pressure scores of clients in the experimental and control group.

\begin{tabular}{|c|c|c|c|c|}
\hline $\begin{array}{c}\text { DBP } \\
(\mathrm{mm} \text { of Hg) }\end{array}$ & \multicolumn{2}{|c|}{$\begin{array}{c}\text { Pretest (DBP) } \\
\text { (Experimental group) }\end{array}$} & \multicolumn{2}{c|}{$\begin{array}{c}\text { Pretest (DBP) } \\
\text { (Control group) }\end{array}$} \\
\hline & Frequency (f) & Percentage (\%) & Frequency (f) & Percentage (\%) \\
\hline $60-79$ (Normal) & 2 & 10 & 1 & 5 \\
\hline $80-89$ ( Pre hypertension) & 11 & 55 & 10 & 50 \\
\hline $90-99$ (Stage-I Hypertension) & 4 & 20 & 7 & 35 \\
\hline$>100$ (Stage -II Hypertension) & 3 & 15 & 2 & 10 \\
\hline Total & 20 & 100 & 20 & 100 \\
\hline
\end{tabular}

PERCENTAGEDISTRIBUTION OF CLIENTSIN EXPERIM ENTAL AND CONTROL GROUP BASED ON THEIR BASELINE ANXIETYLEVEL

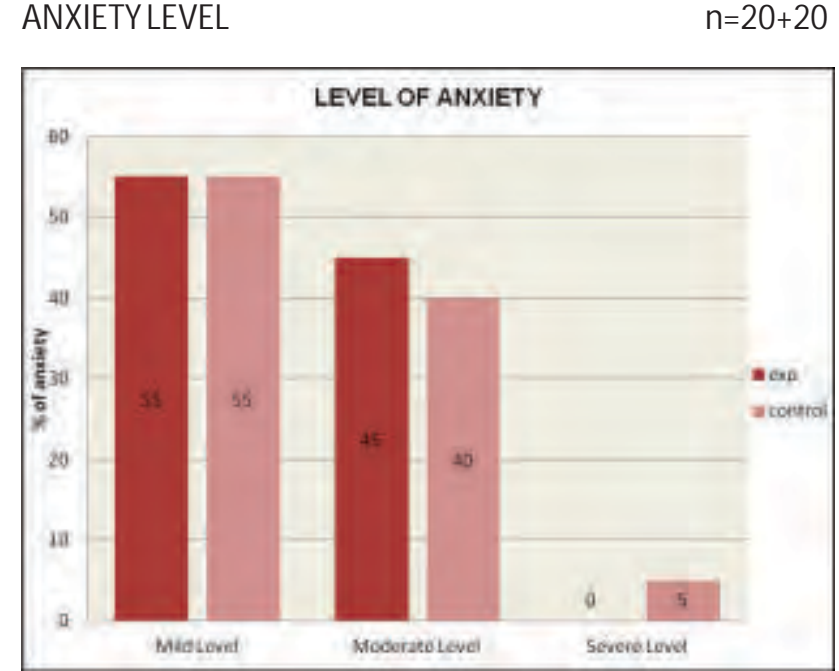

Fig-1: Bar diagram depicting percentage distribution of clients based on their level of anxiety.
PERCENTAGE DISTRIBUTION OF CLIENTSIN EXPERIMENTAL AND CONTROL GROUP BASED ON THEIR BASELINE DEPRESSION LEVEL

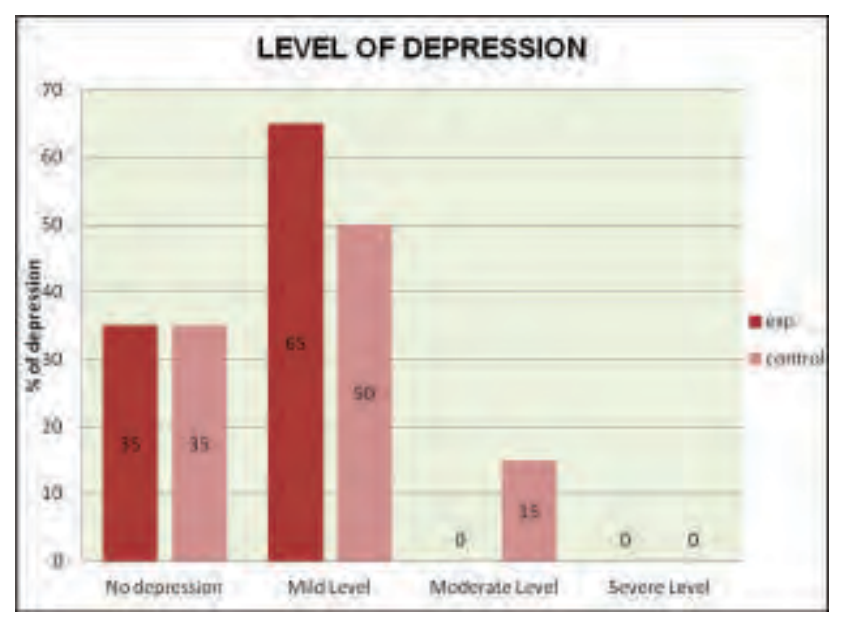

Fig-2: Bar diagram depicting percentage distribution of clients based on their level of depression.

Table 1, 2, 3 and Fig $1 \& 2$ depict the distribution of samples (experimental and control group) with regard to their baseline heart rate, blood pressure, anxiety and depression scores. 
SECTION III: EFFECTIVENESS OF DEEP BREATHING EXERCISE ON HEART RATE VARIABILITY AND BLOOD PRESSURE, ANXIETY AND DEPRESSION LEVELIN THEEXPERIM ENTALGROUP USING PAIRED t-TEST.

Table-4: Paired t-test for pretest and posttest heart rate variability, blood pressure, anxiety and depression level of the clients in the Experimental group. $n=20$

\begin{tabular}{|c|c|c|c|c|c|c|c|}
\hline Variables & Group & M ean & M.D & S.D & 't'-value & df & LOS \\
\hline \multirow[t]{2}{*}{ Heart rate } & Pre-test & $74.50 \pm 3.6$ & \multirow[t]{2}{*}{4.0} & \multirow[t]{2}{*}{3.43} & \multirow[t]{2}{*}{5.210} & \multirow[t]{2}{*}{19} & \multirow[t]{2}{*}{0.001} \\
\hline & Post-test & $70.50 \pm 1.8$ & & & & & \\
\hline \multirow{2}{*}{$\begin{array}{l}\text { Systolic } \\
\text { Blood } \\
\text { pressure }\end{array}$} & Pre-test & $132.50 \pm 13.32$ & \multirow[t]{2}{*}{10.50} & \multirow[t]{2}{*}{10.99} & \multirow[t]{2}{*}{4.273} & \multirow[t]{2}{*}{19} & 0.001 \\
\hline & Post-test & $122 \pm 6.16$ & & & & & $\begin{array}{c}\mathrm{p}<0.05 \\
\mathrm{~S}\end{array}$ \\
\hline \multirow{2}{*}{$\begin{array}{l}\text { Diastolic } \\
\text { Blood } \\
\text { pressure }\end{array}$} & Pre-test & $86.50 \pm 9.88$ & \multirow[t]{2}{*}{7.50} & \multirow[t]{2}{*}{8.50} & \multirow[t]{2}{*}{3.943} & \multirow[t]{2}{*}{19} & 0.001 \\
\hline & Post-test & $79.00 \pm 4.47$ & & & & & $\begin{array}{c}\mathrm{p}<0.05 \\
\mathrm{~S}\end{array}$ \\
\hline \multirow[t]{2}{*}{ Anxiety } & Pre-test & $19.75 \pm 6.773$ & \multirow[t]{2}{*}{16.450} & \multirow[t]{2}{*}{6.236} & \multirow[t]{2}{*}{11.796} & \multirow[t]{2}{*}{19} & 0.001 \\
\hline & Post-test & $3.30 \pm 1.341$ & & & & & $\begin{array}{c}\mathrm{p}<0.05 \\
\mathrm{~S}\end{array}$ \\
\hline \multirow[t]{2}{*}{ Depression } & Pre-test & $10.6 \pm 5.7$ & \multirow[t]{2}{*}{8.5} & \multirow[t]{2}{*}{4.32} & \multirow[t]{2}{*}{8.794} & \multirow[t]{2}{*}{19} & 0.001 \\
\hline & Post-test & $2.10 \pm 2.3$ & & & & & $\begin{array}{c}p \varangle 0.05 \\
S\end{array}$ \\
\hline
\end{tabular}

$\operatorname{ttab}(19)=2.091$

S=Significant

SECTION IV: COM PARISON OF HEART RATE VARIABILITY AND BLOOD PRESSURE SCORES, ANXIETY AND DEPRESSION LEVELBETWEEN EXPERIM ENTALAND CONTROLGROUP AFTER INTERVENTION.

Table-5: Comparison of heart rate, blood pressure, anxiety and depression scores between experimental \& control group based on Independent Sample't'-test. $n=20+20$

\begin{tabular}{|c|c|c|c|c|c|c|}
\hline \multirow{2}{*}{$\begin{array}{c}\text { Group } \\
\text { variable }\end{array}$} & \multicolumn{3}{|c|}{ Difference Values } & \multirow[t]{2}{*}{ 't' value } & \multirow[t]{2}{*}{$d f$} & \multirow[t]{2}{*}{ LOS } \\
\hline & $\begin{array}{c}\text { (Experimental } \\
\text { group- pretest } \\
\text { \&posttest) }\end{array}$ & $\begin{array}{c}\text { M ean SD } \\
\text { (Control group } \\
\text { pretest \& posttest) }\end{array}$ & $\begin{array}{c}\text { Mean } \\
\text { difference }\end{array}$ & & & \\
\hline $\begin{array}{l}\text { Heart rate } \\
\text { scores }\end{array}$ & $4 \pm 3.43$ & $3.1 \pm 3.97$ & 0.9 & 0.767 & 38 & $\begin{array}{c}0.448 \\
p>0.05 \\
\text { NS }\end{array}$ \\
\hline SBP scores & $10.50 \pm 10.99$ & $10 \pm 14.509$ & 0.50 & 0.123 & 38 & $\begin{array}{c}0.903 \\
p>0.05 \\
N S\end{array}$ \\
\hline DBP scores & $7.50 \pm 8.50$ & $0 \pm 8.58$ & 7.50 & 2.775 & 38 & $\begin{array}{c}0.009 \\
p<0.05 \\
S\end{array}$ \\
\hline Anxiety scores & $16.45 \pm 6.23$ & $11.75 \pm 7.46$ & 4.65 & 2.134 & 38 & $\begin{array}{c}0.039 \\
p<0.05 \\
S\end{array}$ \\
\hline $\begin{array}{c}\text { Depression } \\
\text { scores }\end{array}$ & $8.50 \pm 4.32$ & $8.20 \pm 5.53$ & 0.30 & 0.191 & 38 & $\begin{array}{c}0.849 \\
p>0.05 \\
\text { NS }\end{array}$ \\
\hline
\end{tabular}

$\operatorname{ttab}(38)=2.024$. NS $=$ Not Significant

Table 5 reveals a significant effectiveness of deep breathing exercise on reducing diastolic blood pressure and anxiety among patients with coronary artery disease. $(p<05)$ Though there was no statistical significant difference found in the heart rate, systolic blood pressure and depression scores after the intervention between both groups, the pre test and post test scores of the above variables were different. (Heart rate-pre- $74.50 \pm 3.6$, post-70.50 \pm 1.8 ), Systolic BP- pre$132.50 \pm 13.32$, post-122.00 \pm 6.16$)$, depression scores-pre-10.6 \pm 5.7, post-2.10 \pm 2.3 ) 
SECTION V: ASSOCIATION BETWEEN THE BASELINE HEART RATE, BLOOD PRESSURE SCORES, ANXIETY AND DEPRESSION LEVEL WITH SELECTED DEM OGRAPHIC VARIABLES.

Table- 6: Association between heart rate, blood pressure, anxiety, depression scores and Selected Demographic Variables $n=40$

\begin{tabular}{|c|c|c|c|c|c|}
\hline Variable & Age & Gender & $\begin{array}{c}\text { Type of } \\
\text { diagnosis }\end{array}$ & \multicolumn{2}{|c|}{ Co-morbid disease } \\
\hline Heart rate & $\begin{array}{c}0.146 \\
p>0.05\end{array}$ & $\begin{array}{c}0.213 \\
p>0.05\end{array}$ & $\begin{array}{c}0.139 \\
p>0.05\end{array}$ & \multicolumn{2}{|c|}{$\begin{array}{c}0.075 \\
p>0.05\end{array}$} \\
\hline $\begin{array}{c}\text { Systolic Blood } \\
\text { pressure }\end{array}$ & $\begin{array}{c}0.075 \\
p>0.05\end{array}$ & $\begin{array}{c}0.169 \\
p>0.05\end{array}$ & $\begin{array}{c}0.082 \\
p>0.05\end{array}$ & \multicolumn{2}{|c|}{$\begin{array}{c}0.20 \\
p>0.05\end{array}$} \\
\hline $\begin{array}{c}\text { Diastolic Blood } \\
\text { pressure }\end{array}$ & $\begin{array}{c}0.068 \\
p>0.05\end{array}$ & $\begin{array}{c}0.175 \\
p>0.05\end{array}$ & $\begin{array}{c}0.088 \\
p>0.05\end{array}$ & \multicolumn{2}{|c|}{$\begin{array}{c}0.038 \\
p<0.05\end{array}$} \\
\hline Anxiety & $\begin{array}{c}0.076 \\
p>0.05\end{array}$ & $\begin{array}{c}0.252 \\
p>0.05\end{array}$ & $\begin{array}{c}0.108 \\
p>0.05\end{array}$ & \multicolumn{2}{|c|}{$\begin{array}{c}0.089 \\
p>0.05\end{array}$} \\
\hline Depression & $\begin{array}{c}0.072 \\
p>0.05\end{array}$ & $\begin{array}{c}0.237 \\
p>0.05\end{array}$ & $\begin{array}{c}0.129 \\
p>0.05\end{array}$ & $\begin{array}{l}0.006 \\
p \varangle 0.05\end{array}$ & $\begin{array}{c}\frac{\text { Income }}{0.031} \\
p \varangle 0.05\end{array}$ \\
\hline
\end{tabular}

Table- 6 depicts there was significant association found between diastolic blood pressure and depression with Co-morbid disease A significant association was also found between depression and income $(p \varangle 0.05)$.

SECTION VI: CORRELATION OF ANXIETY AND DEPRESSION SCORES

Table- 7: Correlation between Anxiety and Depression scores. $n=40$

\begin{tabular}{|l|c|c|}
\hline Variable & Pearson Correlation $(r)$ & $p$ \\
\hline Anxiety & & 0.008 \\
\cline { 1 - 1 } Depression & 0.414 & $\mathrm{~S}$ \\
\hline
\end{tabular}

\section{S: SIGNIFICANT}

Table-7 depicts a significant positive correlation between anxiety and depression $(r=0.414, p \varangle 0.01)$

\section{Discussion:}

The demographic characteristics of the study indicated that majority of the subjects 31 (77.5\%) were in the age group of 40-59 years which indicates that CAD is consuming highest the productivity capacity of the country. ${ }^{7} T$ The findings of this study reveal that majority $70 \%$ (30) were males, which is supported by another study conducted by the National Heart and Lung Institute which revealed Coronary artery disease among 184 males out of 250 subjects. This signifies the prevalence of coronary artery disease in males compared to the females. ${ }^{8}$

The present study findings revealed $45 \%$ of the subjects were from rural as well as urban background which is contrary to the cross-sectional survey findings of the district of north India which found that prevalence of CAD was 3 fold more in urban area (9\%) and 3.3\% in rural area. ${ }^{9}$ This alerts us that CAD once thought of as a disease of the affluent is now affecting even the rural population.

The present study findings show that CAD was associated with co morbid diseases like hypertension 13 (32.5\%) and diabetes $5(12.5 \%)$ which is supported by similar findings in a study conducted among2259 men in a large industry of northern India which revealed that $(30 \%)$ of them had hypertension and (15\%) of them had diabetes. ${ }^{10}$ Hence co morbid diseases are considered as major risk factors for developing coronary artery disease.

The present study revealed that majority 20 (50\%) of the clients were pre hypertensive and 17 (42.5\%) were hypertensive. $21(52.5 \%)$ had mild anxiety, $17(42.5 \%)$ had moderate anxiety and 23(57.5\%) had mild depression. Similar findings were reported in a study conducted by the National Institute of Health and M edical Research, France on 726 subjects, which revealed that anxiety disorders were associated with a higher risk of coronary artery disease. ${ }^{11}$ These findings indicate the need of counseling patients or having relaxation therapies incorporated as a 
part of cardiac rehabilitation program.

Deep breathing exercise was found to be effective in reducing diastolic blood pressure and anxiety among patients with CAD which is supported by various reviews. ${ }^{12,13}$ No significant reduction in depression scores were found in the study findings which is contrary to the study conducted in Japan which revealed the effect of DBE on depression. ${ }^{13} \mathrm{~A}$ significant association between depression and occupation ( $p=0.051)$, monthly income $(p=0.031)$ and co morbid disease $(p=0.006, p \varangle 0.05)$ was revealed in the present study and anxiety and depression were found to be correlated $(r=0.414, p \varangle 0.01)$. Systematic reviews have also revealed the fact that depression and anxiety are strong risk factors for recurrent cardiac events in patients with

\section{References}

1. Slobodan Ilic, Svetlana Apostolovic. Psychological aspects of cardiovascular diseases. available from: http:// facta.junis.ni.ac.rs

2. Carels, R.A., Blumenthal, J.A, \& Sherwood A. Emotional responsivity during daily life: Relationship to psychosocial functioning and ambulatory blood pressure. International Journal of Psychophysiology, 36, 25-33.

3. James L Januzzi, Theodore A Stern, Richard C Pasternak, Roman W DeSanctis. The Influence of Anxiety and Depression on Outcomes of Patients with Coronary Artery Disease, Archives of internal medicine. Available from: URL:http://archinte.jamanetwork.com.

4. Victoria M arie Wilkins. Religion, Spirituality, and Psychological Distress in Cardiovascular Disease. Available from: URL:http://idea. library.drexel.edu.

5. Kawachi, I Sparrow, D Vokonas. Coronary heart disease/myocardial infarction: Symptoms of anxiety and risk of coronary heart disease: The Normative Aging Study.

6. Daniel E Ford. Depression Is a Risk Factor for Coronary Artery Disease in M en. Available from: http://archinte.jamanetwork.com/article.

7. Singh RB, Sharma JP, Rastogi V, Raghuvanshi RS, M oshiri M, Verma SP, et.al. Prevalence of coronary artery disease and coronary risk factors in rural and urban populations of north. available from: URL: http://www.ncbi.nlm.nih.gov/pubmed

8. M cLaughlin KJ, Hill SJ. Emergency Cardiac Care. Heart and lung journal coronary artery disease. ${ }^{14}$

\section{Conclusion:}

Deep breathing exercise has been used in many integrated psychological intervention like mind body therapy, complementary alternative medicine and so on. But very few literatures have supported the fact that DBE was used as a standalone relaxation therapy for patients with coronary artery disease. This study has proven that practicing deep breathing exercise daily for 2 weeks 2 times a day for 10 min has significantly decreased the anxiety level and diastolic blood pressure of patients with CAD. Hence it can be considered as a cost-effective strategy in the prognosis of the disease.

2006 March; vol.27 (5) 553-61: available from: URL: http:// www.content jour heart- lung. (07.10.2009)

9. Singh RB, Sharma JP, Rastogi V, Raghuvanshi RS, M oshiri M, Verma SP, et.al. Prevalence of coronary artery disease and coronary risk factors in rural and urban populations of north. available from: URL: http://www.ncbi.nlm.nih.gov/pubmed

10. D prabhakaran, pankaj shah, vivek chaturvedi, lakshmy ramakrishnan, ajay manhapra, k. Srinath reddy. Cardiovascular risk factor prevalence among men in a large industry of northern India. Available from URL: http://nmji.in/archives/Volume.

11.Jean M, Joanne Runions. Anxiety and depression after acute myocardial infarction. Heart \& Lung: The journal of Acute and Critical Care 2004. available from: URL: http:// www.sciencedirect.com

12. L Chung, P Tsai, B Liu, K Chou, W Lin, Y Shyu, et.al. Home-based deep breathing for depression in patients with coronary heart disease: A randomized controlled trial. International Journal of Nursing Studies. available from: URL: http:// www.journalofnursingstudies.com/

13. M ori H, Yamamoto H, Kuwashima M, Saito S, Ukai H, Hirao K, et.al. How does deep breathing affect office blood pressure and pulse rate. available from: URL: http:// www.ncbi.nlm.nih.gov/pubmed/

14. Park JH, Bae SH. A systematic review of psychological distress as a risk factor for recurrent cardiac events in patients with coronary artery disease. available from: URL:http://www.ncbi.nlm.nih.gov/pubmed/ 